\title{
1. In quest of sustainable politics and economics of natural resources: a summary of contributions and future research directions
}

\author{
Stella Tsani and Indra Overland
}

\section{INTRODUCTION}

Much of the literature and empirical research in the fields of economics and politics shows that natural resources are a gift from nature that, if properly managed, can support economic development, social prosperity and human welfare. While resources may be naturally available, the design of prudent policies and the use of appropriate economic instruments to best manage them are coupled with significant challenges. These are linked to, among other things, resource-specific characteristics, such as the finite nature of minerals and hydrocarbons, the geographical concentration, the weak links between resource policies and the wider fiscal, social and macroeconomic packages, the difficulties in developing and implementing an optimal socio-economic and environmental policy mix, and the significant risk, uncertainty and change that characterize the intertemporal use of natural resources and related decision making.

In light of the ongoing processes of socio-economic transition towards a sustainable and resilient mode of development and growth, driven by the understanding that humanity can no longer continue along the same socio-economic path with the same policies and models of production and consumption, resource management deserves a careful review and update. Global commitments, regional actions and common target setting, including the Paris Agreement, the European Green Deal, the United Nations 2030 Sustainable Development Agenda and the 17 Sustainable Development Goals (SDGs), give new impetus to debates on the policy and economic challenges and opportunities related to natural resource management. In these debates, the accumulated experience of resource economics and politics offers a solid base of knowledge about the key concerns and practical issues. Complementing the state-of-the-art research on past experience, forward-looking approaches to natural resource politics and economics lay the groundwork for novel research in this area and provide insights on the core issues that policy makers and practitioners in the field should pay more attention to in the near future.

The Handbook of Sustainable Politics and Economics of Natural Resources is a result of precisely this realization - that we need to learn from the past but also to have a clear understanding of the transformative developments ahead, to better prepare a set of policies and economic tools for natural resources that can support sustainable development and resilient growth, economically, socially and environmentally. Driven by this aim, this Handbook brings together state-of-the-art interdisciplinary contributions that consider the economic, environmental, social, financial and technological dimensions of resource policies. This is done with the target and belief that the Handbook advances scientific research in the area, contributes to 


\section{Handbook of sustainable politics and economics of natural resources}

well-informed policy making and constitutes useful reading for academics, researchers, policy makers, advanced students and practitioners in the field.

Contributors to the Handbook examine resource policies to understand the challenges and solutions in a changing environment where the SDGs and climate change form the backdrop for policy making. Towards this end, the authors study the particularities and uncertainty that surround specific resources, regions and institutions and their policies. The Handbook contributions extend into four complementary areas of research and are correspondingly grouped into four parts. Part I and Part II investigate the resource- and region-specific challenges, respectively, that shape national and global policies and developments. Part III focuses on the institutional aspects of resource management and their implications for policy making. Part IV brings together studies on the uncertainties and risks associated with climate change and the requirements of forward-looking resource policies.

The complementary focus areas that determine the structure of the Handbook are interlinked, and to some extent overlap. For instance, the study of oil price volatility in Kazakhstan relates to resource-specific challenges (e.g., the volatility of hydrocarbon prices) but also region-specific developments (e.g., the dependence of Kazakhstan/Central Asia on oil and gas, and their vulnerability to oil price fluctuations, macroeconomic and fiscal volatility). This topic could also link to institutional characteristics (i.e., the quality of political institutions, such as transparency in revenue allocation, the rule of law, or the presence of specific sovereign wealth funds that are used to protect the economy from adverse shocks). These overlaps indicate that the subjects addressed in this Handbook are indeed related to multidimensional challenges and should not be studied in isolation. While the structure of the Handbook is based on the thematic focus areas for the ease of the reader, the interlinkages between the thematic areas are also underlined and readers may want to keep them in mind.

This chapter provides a comprehensive overview of the contributions included in the Handbook, highlighting the core points of policy interest and the results, with a focus on recommendations and directions for future research. The content of the Handbook is non-exhaustive; it is well understood and acknowledged that the topics of relevance to sustainable politics and economics for natural resource management extend well beyond a single volume. However, this Handbook makes a start in bringing together consolidated knowledge and suggestions for further work in the field. Hopefully, this will provide useful material and an impetus for future similar collective works and updates to this Handbook. In the same way, the insights and recommendations that can be extracted from the contributions to this Handbook are far more than those that are summarized in a single chapter. This chapter therefore provides only a snapshot of the contents, outlining the individual contributions with their most significant insights and recommendations. The snapshot provided in this chapter follows the structure of the Handbook. Section 2 presents the contributions that focus on resource-specific characteristics, policy and economic challenges. Section 3 summarizes the works that have a regional focus. Section 4 presents contributions to the Handbook that investigate the institutional aspects of resource management and their implications for policy making. Section 5 summarizes the chapters that relate to the uncertainties, socio-economic shocks and risks associated with climate change and the forward-looking requirements of resource policies. The last section wraps up the chapter with some concluding remarks. 


\section{RESOURCE SPECIFICS AND CONSIDERATIONS FOR POLICY MAKING}

If properly managed, natural resources can be transformed into surface assets. Nevertheless, this transformation has been proven to be a practical challenge. In Chapter 2 of this Handbook, Koh discusses the role that natural resources play in the economic development of different countries. Failures and difficulties in resource-based economic growth and development are related to the exhaustible nature of resources (e.g., point, finite resources) and to the economic particularities related to volatility, information asymmetry, rent seeking, technical requirements and incentive distortion. The analysis provided by Koh shows that the design of the institutional framework and fiscal regime are crucial elements in maximizing economic returns from natural resources, a point that is highlighted in several other contributions (see also Coutinho and Tsani's discussion in Chapter 17). Koh's analysis shows that economic diversification and structural policies are key to sustainable growth and development linked to natural resources. Conclusions relate to the policy aspects and economic tools that can support prudent natural resource management. These include robust regulatory and fiscal regimes applied to all industry actors and essential elements such as licensing, allocation of rights, fiscal terms, health and safety regulations and environmental standards. It is also suggested that countercyclical fiscal policy, pursued through appropriate fiscal tools such as sovereign wealth funds (covered in detail in Chapter 16 by Carpantier and Vermeulen and also in Chapter 17 in the work of Coutinho and Tsani), protects against boom-and-bust cycles. Additional policies to support resource-related economic development, indicating areas for future research and policy emphasis, relate to the identification and implementation of appropriate monetary and exchange-rate policies, economic diversification to increase new market opportunities and diversified foreign direct investment, and careful spatial, human capital, institutional and governance policies. In Chapter 3, Månberger projects an understanding of the challenges related to finite resources into alternative future developments by looking at the interactions between renewable energy penetration, transport electrification and the demand for metals. His work identifies the essential metals for renewable energy technologies. Månberger provides a condensed review of the metal requirements of alternative renewable energy technologies, shedding light on the potential metal demand developments that might result from the transformation of the global energy system, robust climate change mitigation actions and sustainability transitions. The analysis shows that while metals are finite and geographically concentrated, like hydrocarbons, they may generate less revenue and expose owner countries to less resource dependence, with lower fiscal and macroeconomic volatility transmission. While the macroeconomic and fiscal impact of mineral extraction for renewable energy technologies may be deemed less severe as compared to the fiscal impact of hydrocarbon extraction, the local impact of mineral exploration and commercial exploitation may be significant, both in social terms (e.g., conflict) and economic terms (e.g., local economic development, employment and income generation). Impacts are also discussed in terms of the scale of the mining activities (e.g., the impacts of large-scale vs small-scale mining).

There are links between Chapter 3 and other chapters. Extensions to the implications of mining scale are also discussed in Chapter 12 on small-scale mining in Sub-Saharan Africa, which Hilson, Sauerwein and Cardoso discuss through the prism of rural resilience and the SDGs. Both the works of Månberger and Hilson et al. highlight the local impact of natural resources and the need to understand them better and design appropriate regional- and 
community-level policies. The local impact and policy focus are also examined in Chapter 15 in the work of Kalyuzhnova on the appropriate policies for local development and resilience. All these works show the importance and priority for better understanding of the local impact of certain types of natural resources (metals, minerals and hydrocarbons) that are characterized by small-scale geographical concentration, capital intensity and their finite nature.

In Chapter 4, Sagbakken, Isataeva, Overland, Pranadi, Suryadi and Vakulchuk investigate coal, a depletable resource that is characterized by geographical concentration and capital intensity. Most importantly, coal is subject to significant phasing out and global decarbonization efforts. In their analysis, the authors examine the global shift away from coal and the contrasting expansion in coal mining and consumption in Southeast Asia, in an attempt to understand the connections and disconnections between the coal sector in the member countries of the Association of Southeast Asian Nations (ASEAN) and global climate policy. Acknowledging the impact of moving away from coal and targeting the reduction of $\mathrm{CO}_{2}$ emissions, the authors discuss the risks of coal opt-in in the ASEAN region. The analysis shows that these relate to energy insecurity, the undermining of the ASEAN international climate commitments, neglect of significant untapped renewable energy potential, and impaired health and environmental quality. Despite the ease of access and seeming abundance that make coal an attractive resource in the ASEAN region in the short term, the negative impacts across a number of sectors that are crucial for the ASEAN economies, such as tourism and agriculture, indicate that the least attractive option would be to continue the exploitation of coal in the context of decarbonization and sustainability transition. It is this increasing social understanding of the dangers related to coal that has given power to local civil society in resisting efforts to continue along the same coal-dependent path in the ASEAN.

This indicates the potential for empowerment and transformation of social understanding of the impact of using conventional energy sources, which are expected to intensify in the future as a result of efforts to implement the SDGs and shape the exploration and exploitation of conventional resources such coal in the immediate future. The analysis of the ASEAN region in Chapter 4 indicates the socio-political areas that deserve special attention to better understand and prepare for future developments in conventional energy sectors. These include minority and local community rights, regional versus global political divides, national and international cooperation and coordination, development of activist networks and international civil society. Some of these points are also highlighted in the work of Inglesi-Lotz (Chapter 13) that focuses on the African continent.

The importance of regional and global policy alignment, of national and international cooperation and coordination, is also noted by Tsani, Apostolaki and Koundouri in Chapter 5. The authors consider the case of water resources and the importance of integrating socio-economic, technological and environmental management. The authors discuss regional policies on water management with a focus on the EU Water Framework Directive, a blueprint for sustainable water management. While the Directive shares several characteristics and end targets with the UN SDGs, it still lacks the fully developed tools that allow for the integrated sustainable management of water resources. The authors discuss methodological considerations and potential solutions for integrated water management, with a focus on the economic tools for full water cost recovery - that is, methods that allow for the capture of the total costs and benefits related to water, whether economic, social, technological, financial or environmental. This work provides insights into the ways that these economic tools can be updated to achieve sustainable management of water resources. This chapter also discusses the need to examine regional and 
global cooperation pathways to achieve universal implementation of methods that allow for full water cost recovery.

Focusing on the policy and economic challenges related to conventional energy sources, Girard, Kudebayeva and Toews study the relationship between oil price booms, income and satisfaction in Chapter 6 with the empirical analysis of data for Kazakhstan. The authors explore time, sectoral and spatial variations to identify the impact of the recent oil boom on an oil-dependent economy. The analysis contributes to our understanding of the impact of resource policies by highlighting the economic and political consequences of information about future point resource wealth and the idea of inflated expectations. In addition, it indicates that the prospect of resource wealth might unleash political forces leading to changes in people's perceptions, group-level dissatisfaction and potential conflicts. Quickly changing aspirations can easily be exploited by political actors to engage different groups. The results are in line with the news-shock literature and provide insights into the way that private sector information changes people's aspirations to benefit from a resource price boom. Linking this work to the analyses presented in Chapters 2 and 3, an interesting research path emerges for future work on the implications of price shocks for the nations emerging as core global producers of finite resources that are important for renewable energy technologies and climate change mitigation (e.g., minerals, metals and rare earths).

\section{REGIONAL RESOURCE POLITICS AND IMPLICATIONS FOR GLOBAL POLICIES AND ECONOMIC DEVELOPMENT}

Part II of the Handbook gathers chapters with a regional focus to their analysis. Global climate change and sustainable development targets are defined by commitments under global climate agreements (e.g., the Paris Agreement) and the United Nations 2030 Sustainable Development Agenda. At the regional level, the European Green Deal constitutes an action paradigm with multiple implications for other countries in the world. As the EU is a significant trading partner of developed and developing regions worldwide, the European Green Deal will directly and/ or indirectly impact other regions and countries. Part II starts with a presentation of the Green Deal and a discussion of the related financing mechanisms from Busse, Dreute, Isaila and Vinhas de Souza in Chapter 7. The European Green Deal is an ambitious policy framework that seeks to ensure continued European global climate leadership and galvanize the private sector to speed up the energy and climate transition, in an effort to live up to the promises of the Paris Agreement and the SDGs. The ramifications of target-setting actions to be taken and outcomes of the Deal are important for EU member states and for the rest of the world. While Europe is moving relatively swiftly forward with climate change and sustainable development policies, major energy producers and consumers worldwide with significant reserves and market power in conventional energy sources are operating with different priorities and speed. This coexistence of different policy priorities and political agendas related to climate change will have a profound impact on global decarbonization, climate change action and the sustainability transition. This is understood not only from the work of Busse et al., but also from the other works that are included in Part II of the Handbook. All these works indicate the need for future research to shed more light on these discrepancies and on their policy and economic ramifications. 
In Chapter 8, Makarov recognizes Russia as a case of special interest in global climate change and sustainability transition. Russia remains an important country for global climate change mitigation. Nevertheless, the national policy stance to date has demonstrated weak ambitions to reduce greenhouse gas (GHG) emissions. While international commitments have been made, no real impact of these is seen in policy making. In an attempt to understand this stance, which is similar to that of other large energy producers, factors such as the country's heavy dependence on fossil fuels, the industrial structure of the economy and reliance on energy-intensive industries, as well as climate scepticism in public discourse, emerge as noteworthy. While these explain developments on the ground, they also indicate the threat that Russia and other resource-dependent emerging economies face. Dangers are related to the outdating of the economic model based on extraction and exports of fossil fuels (this dimension is also discussed in Chapters 4 and 9). At the same time, Makarov identifies new opportunities connected with significant potential for cheap emissions reduction in Russia. Changing the industrial base is also identified as an opportunity for Saudi Arabia in Chapter 9 by Tsani and Najm and for Israel in the work of Palatnik et al. presented in Chapter 10. All studies indicate the need to better understand the underestimated opportunities for meaningful change in energy-intensive industries and countries dependent on conventional energy sources, something that is largely disregarded by national politics due to short-term political goals.

This conclusion is also drawn in the work of Tsani and Najm, presented in Chapter 9. The authors conduct a critical assessment of the political economy of energy in Saudi Arabia and the impediments to achieving a national sustainability transition. The analysis shows that while current political will is seeking various diversification plans and environmental initiatives, the pace of change remains largely insufficient and lacking coordination. Tsani and Najm, like Makarov in Chapter 8, document the lack of sufficient action, determined mostly by the oil dependence of the economy and the importance of individual preferences for sustainability transition. (The issue of preferences is further formalized in Chapter 21, where Tsani and Kozlova discuss methodological advances regarding behavioural representation in decision making relating to energy and the environment.) The analysis of Tsani and Najm extends to arguments on the timely action from large oil producers like Saudi Arabia and related advantages coming from long experience with the management of the oil and gas sector, accumulated oil wealth and related labour market policies. The authors point out that the debate on energy transition in oil-rich countries disregards their competitive advantages related to the extensive experience and established capacity to produce at low cost and to optimize their production and sectoral management for many decades. Diversification strategies that seek to deploy strengths related to managerial experience, labour market policies, capital availability and established supply chains could yield significant benefits for large oil producers.

In Chapter 10, Palatnik, Davidovitch, Krey, Sussman, Riahi and Gidden provide a comprehensive, economy-wide analysis of the alternative pathways for energy-related carbon emissions reduction in Israel. The modelling results show that ambitious $\mathrm{CO}_{2}$ reduction policies can be implemented with a minor impact on gross domestic product (GDP) growth. Decarbonization of the Israeli economy will necessarily be based on increasing the electrification of transport and industry and on generating power from renewable energy resources (this highlights the timely insight offered by Månberger's analysis of the demand for metals, presented in Chapter 3). Chapter 10 provides valuable insights for the design of clean energy policies that can enable the achievement of sustainability targets and methodological advancements that can help decision makers to understand the options available to them to accomplish 
ambitious decarbonization and sustainability goals. Important conclusions and indications for future research point to the opportunities related to long-term strategic planning that can achieve both emissions reductions and economic growth through the synergy between adopting emissions reduction targets and upgrading infrastructure and technology.

Looking at both the increasing demand for renewable energy and the pressure put on natural resources, in Chapter 11, Xenarios, Laldjebaev, Schmidt-Vogt, Buurman and Araral present the case of hydropower generation in Central Asia and mainland Southeast Asia. The analysis highlights the impact of the increasing growth of China and the need to develop the region's energy sources. While hydropower is a promising alternative for Southeast and Central Asia, emerging as a new bonanza for the two regions, it also gives rise to territorial disputes, uneven access and exploitation of the natural resource at hand, with important economic, social and environmental implications. The analysis indicates emerging conflicts with different sectors (e.g., agriculture and tourism) as the result of water use for energy production. The importance of skewed distribution of economic benefits is also discussed in relation to hydropower, indicating the need to better understand and further investigate the similarities between the management of depletable and renewable energy sources related to institutional capacity and the appropriateness of the policy approaches and economic tools used.

In the context of mining, Hilson, Sauerwein and Cardoso discuss in Chapter 12 the potential benefits of co-existence of different economic activities in local communities, as a way of more quickly achieving the SDGs. The authors discuss the case for formalizing and supporting artisanal and small-scale mining (ASM) - low-tech, labour-intensive mineral extraction and processing - in Sub-Saharan Africa, by focusing on how the sector enhances food security and builds resilience in the region's vulnerable rural communities. While Sub-Saharan Africa is characterized by a long history of ASM and smallholder activity, rarely have the synergies between these activities, food security and resilience been examined in the policy making or in the international aid and development programmes targeting the region. The analysis indicates not only the gaps in current approaches to resource-based economic development, but also future directions in policy making and formal analysis of the synergies between the resource sector and other complementary policy areas that require urgent attention (e.g., food security, social cohesion, community resilience and adaptation to climate change).

In Chapter 13, Inglesi-Lotz provides a bird's-eye view of resource management in the African continent. In line with the analysis of other contributors to this Handbook, Inglesi-Lotz also points to the need to carefully examine and understand local resource-based economic, social and industrial development, with the aim of creating a local and internationally competitive supply chain. Inglesi-Lotz discusses the need to explore policies that will provide synergic benefits in both natural resource exploitation and improving the quality of human capital. The work of Inglesi-Lotz adds to the arguments in favour of a more careful future study of local conditions and characteristics for better addressing sustainability and green transition challenges. This is also a basic stance in the works included in the third part of the Handbook.

\section{$4 \quad$ INSTITUTIONS AND RESOURCE POLICIES}

In the first two parts of the Handbook, the focus rests with resource and region-specific insights. While the outcomes offered in this regard are important, the works included in these parts also provide other indirect results and insights. Related insights include the importance 
of institutions for prudent resource economics and politics. This is explicitly recognized as an important area of past and future investigation in the third part of the Handbook. The works included in this section refer explicitly to the importance of institutions, whether formal or informal, and provide useful documentation of the status of knowledge and future priority areas of policy making and research.

In Chapter 14, Arminen, Pekkanen and Sappinen discuss a prevalent topic in the field of resource economics and politics: institutional quality and the prevalence of corruption. The authors discuss the role of resource policies in alleviating or exacerbating the corruptionresource trap by surveying the existing literature on timber, oil, precious metals and diamonds. Their recommendations point to the importance of grasping the notable differences between natural resources in their susceptibility to the resource curse and related issues. They also indicate the need for further work on understanding the differences in institutional quality and the level of corruption in particular, to better characterize and explain the heterogeneous development paths of resource-abundant countries. In this sense, the focus should be not only on economic development, but also on social and institutional development. At the global level, the analysis shows that universally effective policy recommendations cannot be made because the success of policies is highly context-dependent and varies between resources, regions and countries. In this regard, future research may fill more knowledge gaps through analysis at the community level.

In Chapter 15, Kalyuzhnova examines the role of institutional capacity for successful local content policy, an instrument used for maximizing the impact of natural resource development. Sustainable local content policies target the use of domestic sources at different stages throughout the value chain to generate local employment, strengthen cross-sector benefits and create knowledge and skills linkages. Kalyuzhnova discusses the importance of policies targeting domestic producers and the role that appropriate institutional contexts play in this regard. For successful design and implementation of local content policies, institutional capacity in resource-rich countries should be such that it enables open access to international expertise in the areas of technology and management, industrial diversification, innovation-led growth, setting up and encouraging open communication and participation, and more inclusive decision-making processes. Kalyuzhnova points to the importance of decision makers considering local content requirements and negotiations for successful implementation. Moreover, it shows the direction forward for related scientific research, which needs to provide further knowledge on the institutional changes to any aspect of resource development and management for an all-encompassing and overarching management strategy, including all government and non-government functions.

Carpantier and Vermeulen shift the institutional focus to the macroeconomic management of resource wealth in Chapter 16. The authors review the experience of commodity-based sovereign wealth funds (SWFs), as part of a larger group of more than 100 SWFs around the world. In the face of headwinds due to the end of the commodity super-cycle and the gradual reduction of the global imbalances, Carpantier and Vermeulen review the alternative institutional design for reaching the objectives of SWFs. Paving the way for future research, the authors identify that the success of SWFs in fulfilling their objectives has so far been under-investigated. They also indicate areas requiring a careful consideration related to macroeconomic stabilization and the understanding of SWFs' contribution in supporting the non-commodity-related exporting industries. In terms of intergenerational transfers, SWFs need to be examined through the prism of the global evolution of the international net finan- 
cial position of the countries that have set up the SWFs. Last, what also appears important is the identification of better governance structures for SWFs in managing trade surpluses and the impact of SWFs in institutional performance and governance in resource-rich countries. Research efforts in this context are critical, as SWF countries might well face greater challenges in the coming decades, as SWFs emerge as important players in the global financing of climate change mitigation and sustainable development actions (Tsani and Overland, 2020; Tsani et al., 2021).

Coutinho and Tsani examine the role of SWFs under the topic of fiscal procyclicality and macroeconomic volatility that are evidenced in many resource-rich countries. Chapter 17 presents their detailed review of the work published to date on the links between macroeconomic volatility and fiscal policy in resource-rich countries and on the role of institutions. The literature review shows that fiscal pro-cyclicality in resource-rich countries remains under-investigated. Few recent studies attempt to address this issue by providing evidence that fiscal policy has been pro-cyclical in resource-rich countries. Linking this subject to institutional quality and explicit fiscal tools for macroeconomic management of natural resources, such as SWFs and fiscal rules, analysis shows that countries with stronger institutions have been better able to cope with the challenges of natural resource wealth management. While arguments in the literature point in this direction, the empirical and country evidence on this matter remains inconclusive. Coutinho and Tsani show that a systematic analysis of fiscal policy responses in resource-rich countries and of the fiscal arrangements (i.e., fiscal rules, SWFs) can offer valuable contributions to the understanding of resource economics and politics for sustainable resource management.

Beyond national policies and institutions, international actions and institutional capacity also have a significant impact on the sustainability transition and climate change mitigation achieved by countries worldwide. This argument is acknowledged in this Handbook and examined in detail in the work of Doussis and Espa, presented in Chapter 18. Coupled with a legal perspective, this chapter discusses the importance of conceptualizing, assessing and quantifying the effectiveness of international legal institutions and provisions for the sustainable management of natural resources and the implementation of the SDGs. Doussis and Espa discuss the methodological challenges of developing and implementing quantitative measures of the performance of legal systems and the meaningful contributions that such measures could provide to multiple agreements. In support of future work in the field, Doussis and Espa discuss the pros and cons of tailoring the choice of suitable legal indicators for clusters of agreements, either on a natural resource basis (e.g., agreements on the protection of water) and/or on a treaty basis (e.g., the Paris Agreement). The work presented in Chapter 18 prepares the ground for more interdisciplinary research on the methodological framework for the development of legal indicators to be employed in the assessment of SDGs implementation and performance relating to resource protection, conservation and sustainable socio-economic development.

In Chapter 19, Zagonari adds in a novel and challenging way to the debate on the links between institutional characterization, resource management and SDGs implementation. His work provides a first empirical assessment within a single analytical framework of the links between different religious and secular ethics frameworks and the conservation of resources (water) and biodiversity. His work provides theoretical evidence that both religious and secular ethics can support resource conservation, by stressing either respect for nature and non-human beings or reciprocity for future generations. The statistical results summarized in 
Chapter 19 show that religious ethics have a beneficial impact on resource and biodiversity conservation, while secular ethics have a beneficial impact on biodiversity conservation. In terms of policy reliability, Zagonari finds that neither religious nor secular ethics are reliable policies to achieve resource conservation. The work of Zagonari indicates the need to better understand the relationship between informal institutions, resource management and sustainable development, and to further investigate the differences between informal institutions in different countries and how these explain the divergence in sustainability and climate change action in those countries.

\section{CHANGE AND UNCERTAINTY IN RESOURCE POLICIES}

Parts I-III of the Handbook provide fresh insights on topics that have long been debated in the economics and politics literature on natural resources. This supports the state-of-the-art provisioning of the Handbook. Nevertheless, any attempt to build a holistic understanding of the current state of resource politics and economics and the challenges lying ahead for policy makers and researchers in the field would be incomplete if emerging trends in the literature and topics gaining momentum in the recent past were disregarded. Part IV of the Handbook takes a forward-looking approach to issues of resource politics and economics by looking at recent and emerging trends in the literature relating to the national and global policy scene, uncertainty, risk and unanticipated socio-economic shocks.

In Chapter 20, Papandreou provides an overview of the literature on stranded assets and financial system vulnerability. This follows burgeoning interest in the risks associated with stranded assets. The review of alternative definitions of stranded assets and climate-related risks reveals the plethora of their links to the financial system. Two main channels of climate-related risks are discussed in depth: risks of physical impacts from climate change and risks associated with the transition to a low-carbon economy. The analysis shows that the financial system is not yet prepared to adequately account for the potential links and the low responsiveness with corrective policies so far. The study indicates the special challenges and threats to financial stability associated with the sustainability transition, which need to be thoroughly understood and addressed in the years to come.

Tsani and Kozlova discuss methodological approaches to the interaction between the economy, the environment and the energy system in Chapter 21. While traditional models can adequately capture the macroeconomic conditions and drivers of resource use and energy interaction with the rest of the economy-environment system, they may largely disregard agents' behavioural characteristics. Following landmark global and regional actions to address climate change and the shift to green energy, economies and societies have entered a new era of technological revolution, with green energy technologies developing fast and with ever-decreasing production costs. The development of these technologies will inevitably transform the energy sector at unprecedented levels. Moreover, it will introduce significant uncertainty and several challenging questions for policy making related to energy. The analysis shows that questions related to investors' attitudes and decision making in conditions of uncertainty and the effects of retroactive policy changes and technology learning emerge as being of primary importance for energy modelling and energy policy making. Such behavioural aspects and changes cannot be captured adequately by the energy-economy models developed so far. Methodological and conceptual developments to address these limitations look at the usefulness of real options 
models, indicating directions for future research and areas of policy making where such tools could prove useful.

Agliardi and Spanjers discuss ambiguity and risk in the context of financial markets, climate change policies and investor behaviour in Chapter 22. The authors start their analysis with the realization that uncertainty and risk from climate change represent one of the most significant and complex challenges facing the world this century. They also acknowledge that to sustain the transition towards a low-carbon economy, a huge number of financial resources are needed. Nevertheless, investments face ambiguity and risk. Agliardi and Spanjers provide a brief survey of the different approaches to ambiguity in the literature. They examine the effects of 'deep' uncertainty on firms' decisions to issue green bonds in a structural model, where there is ambiguity about the effectiveness of the environmental projects that have been financed and the investors' 'green perception' in portfolio choices. Their analysis shows that ambiguity affects defaults, credit spreads and the so-called 'greenium' or green premium, and impacts on investors' optimal portfolio decisions, potentially impeding the financing of green projects. The results show the need for the design of policy measures and initiatives that can foster transparency through standardized definitions and disclosure requirements, to reduce the 'deep uncertainty' experienced by investors.

Chapter 23 illustrates the discussion on SWFs with the recent developments in Azerbaijan and its State Oil Fund. Countries sitting on substantial revenues coming from natural resources ought to be in a better position to address unexpected socio-economic shocks like the COVID-19 pandemic. Ahmadov, in his analysis of the experience of Azerbaijan with the pandemic and the use of the State Oil Fund for emergency response, indicates the risks and opportunities and the importance of transparency and accountability. The review indicates that setting policy priorities correctly and aiming for transparency and accountability are very important. These preconditions become imperatives for successful operation and mobilization of resource wealth in times of crisis and unexpected shocks.

Widdershoven in his analysis in Chapter 24 argues that COVID-19 may be one of the unexpected bumps in the road to energy transition, adding to the economic and financial constraints. While energy transition is defined as a period where conventional energy supplies will be complemented and replaced by renewables and new energy sources, scenarios and expert analysis show that in the coming decades oil and gas will have an important share in the global energy production mix. At the same time, policy and investor actions intensify for divestment from hydrocarbon assets and no financing of hydrocarbon projects. The analysis discusses the implications of energy transition and underfinancing in the oil and gas sector for future meeting of energy demand and for the socio-economic development of hydrocarbon producers and developing regions, indicating the uncertainties that surround the oil and gas producers but also the end users of conventional energy sources.

This review of the works included in the Handbook of Sustainable Politics and Economics of Natural Resources has revealed the plethora of issues of policy and economic relevance that require careful attention and adequate understanding for sustainable resource management. Following a brief overview of the individual contributions to the Handbook, a collection of broad-brush conclusions and directions for future research is presented in this final section. 


\section{Handbook of sustainable politics and economics of natural resources}

First, successful resource management in social, economic, technology and policy terms should address challenges all the way from resource discovery to revenue management. Research in this area should look at the resource specifics and the links between challenges and opportunities at the different stages of resource exploitation.

Second, policy and economic solutions to challenges related to natural resources require community-level and local assessment in tandem with the wider macroeconomic analysis. Empirical and theoretical works in this area need to shed more light at the micro level and enrich existing knowledge obtained from a macro perspective.

Third, natural resource-specific characteristics matter to the analysis and to the design and achievement of sustainability transition. Point, finite natural resources, such as minerals, metals and hydrocarbons, expose economies to considerable economic challenges, while they may also impact on the transition speed and coordination of policies and targets in resource-dependent economies. The scientific community can look further into what resource dependence means for the transition path and speed of economies worldwide.

Fourth, policy choices to continue using the same resources and energy sources (e.g., hydrocarbons) expose economies to the risks of being left behind in technological innovation, and of not achieving socio-economic transformation in a timely and cost-effective manner. Thus, it seems important to understand and better characterize incentive provisioning in times of socio-economic and technological transformation.

Fifth, meeting ambitious climate targets may pose an opportunity for structural change and diversification of economies away from dependency on conventional energy sources. These opportunities should be understood, quantified and clearly communicated to policy makers and the wider community.

Sixth, prudent management necessitates the development of appropriate tools (e.g., models or fiscal mechanisms) and coordination at the micro level (e.g., at the level of investors or sectors) and at the macro level. To develop future policies and recommendations, it is necessary to look at experience (e.g., experience with fiscal rules, sovereign wealth funds or local content) and extract useful conclusions for actions in times of uncertainty and where greater flexibility is needed.

Seventh, risk and uncertainty remain crucial for sustainable development and climate change action, as they affect investors' decisions and the channelling of adequate capital towards the financing of sustainability transition. A key challenge for policy makers and researchers is to understand their impact and to appropriately capture them in the decision-making process. Future research should target this challenge.

Eighth, agendas of countries worldwide, the presence of nationally and/or regionally specific targets, resource abundance, unforeseen developments and socio-economic characteristics play a key role in the way forward. Thus, coherence of national-global actions and target priorities in the policy sphere should be better grasped and analysed to support timely and meaningful alignment of policies. In relation to this, the importance and efficiency of international law and institutions need to be better understood.

Ninth, the decline in demand for conventional energy sources and the increase in demand for renewable energy may impact on regional outlooks in the near future and on the economic and political relationships between regions and countries in the world. These changes need to be identified and analysed at country, regional and global levels.

Tenth, institutional capacity, cooperation and identification of the formal and informal 'rules of the game' that play a part in resource management are crucial to sustainable devel- 
opment and call for a thorough understanding from the perspective of both policy making and scientific research.

Last, the experience with the COVID-19 pandemic indicates that the related conceptualization and careful economic and policy design are essential not only for the long-term sustainable development, but also for the resilient and efficient resource management in times of unforeseen socio-economic shocks.

\section{REFERENCES}

Tsani, S. and Overland, I. (2020). 'Sovereign wealth funds and public financing for climate action'. In W. Leal Filho, A. Azul and L. Brandli et al. (eds), Climate Action (Encyclopedia of the UN Sustainable Development Goals series). Cham, Switzerland: Springer.

Tsani, S., Riza, E., Tsiamagka, P. and Nassi, M. (2021). 'Public policies, one-health and global inequalities under the Covid-19 lens'. In W. Leal Filho, A. Azul and L. Brandli et al. (eds), Reduced Inequalities (Encyclopedia of the UN Sustainable Development Goals series). Cham, Switzerland: Springer. 